\title{
The PHQ-2 as a Screening Tool for Clinical Depression in a Primary Eye-Care Clinic
}

Matias DellaBella, OD, MS

College of Optometry,

State University of New York

Steven H. Schwartz, OD, MA, PhD

College of Optometry,

State University of New York

Leon Nehmad, OD, MSW

College of Optometry,

State University of New York

\section{ABSTRACT}

Purpose: Screening tests for clinical depression, a highly prevalent and often disabling condition, have not been investigated in primary-care eye settings. The purpose of the present study was to determine the percent of patients in an urban primary-care eye clinic who fail the PHQ-2 screening tool. The PHQ-2 is an ultra-short screener consisting of 2 items regarding mood and anhedonia.

Methods: The two-question PHQ-2 was administered (as part of a larger questionnaire that included data on gender, age, and ethnicity) to patients seated in the Primary Care Clinic of the SUNY College of Optometry [University Eye Center] in Manhattan, NY. A total of 739 surveys were completed over a two-month period, with a completion rate of $69 \%$. All surveys were completed anonymously, and unfinished surveys were not included in the final data set.

Results: The demographics collected in this study mirror those of the population that this clinic serves; overall very diverse, with good representation from each age group. Thirteen percent of the sample received a score of 3 or higher, the standard cutoff score for failure of the PHQ-2.

Conclusions: The failure rate on the PHQ-2 in a primary eye-care, urban population approaches that found in general medical practice, suggesting similar rates of clinical depression. Thus, the PHQ-2 may be a beneficial tool for screening for depression, however, it is important to follow-up with a referral to a mental health specialist.

KEYWORDS

depression, dysthymia, PHQ-2, screening, primary eye care 
The lifetime prevalence of major depression may be as high as $16 \%{ }^{1}$ About $5-10 \%$ of patients in primary care settings suffer from major depression, while dysthymia, a chronic low-grade depression, affects 2 to $4 \%$ of this population. ${ }^{2}$ These conditions result in significant suffering, morbidity and mortality. ${ }^{3,4}$ Major depression is a leading cause of disability in adults, and is expected to soon rank second only to heart disease worldwide. ${ }^{5,6}$ The only chronic condition that is more prevalent in general medical practice is hypertension. ${ }^{78}$ Depressed patients are more likely to attempt or commit suicide. ${ }^{9}$

Despite the increasing availability of effective treatments, ${ }^{10-14}$ both medical and psychological, it is estimated that as few as $22 \%$ of patients with major depressive disorder receive appropriate care. ${ }^{1}$ Since symptoms may not be apparent to the practitioner during routine primary-care medical encounters, there is great interest in developing screening surveys that can be employed in such settings to effectively screen for this disease.,15-17 To encourage the use of these screening tools in primary-care medical practice, where time constraints make efficiency a major consideration, the trend has been toward the use of shorter instruments, including ultra-short (one-, two-, three- and four-item) surveys. ${ }^{3,4,16,18-32}$

The most widely studied of the ultra-short screening surveys, the PHQ-2, consists of the first two items of the longer nine-item Patient Health Questionnaire (PHQ-9). ${ }^{16,17}$ The two questions, which are based on symptoms specified by the Diagnostic and Statistical Manual of Mental Disorders, Fourth Edition (DSM-IV), concern mood and anhedonia (Table 1). ${ }^{33}$ The PHQ-2 has been studied in various clinical populations, including primary care, geriatric, cardiology, obstetrics-gynecology and general medical.,16,18-27,29-32 The most detailed studies with primary-care populations found sensitivities ranging from $79-83 \%$ and specificity ranging from $86-92 \% .{ }^{16,23,25}$ These findings point to its possible utility as a tool for screening patients seeking primary care services. ${ }^{25}$

Table 1: Patient Health Questionnaire-2 (PHQ-2)

\begin{tabular}{|c|c|c|c|c|}
\hline $\begin{array}{l}\text { Over the last } 2 \text { weeks, how often have you been } \\
\text { bothered by any of the following problems? }\end{array}$ & Not at all & Several days & $\begin{array}{l}\text { More than half } \\
\text { the days }\end{array}$ & $\begin{array}{l}\text { Nearly every } \\
\text { day }\end{array}$ \\
\hline a. Little interest or pleasure in doing things & $\square$ & $\square$ & $\square$ & $\square$ \\
\hline b. Feeling down, depressed, or hopeless & $\square$ & $\square$ & $\square$ & $\square$ \\
\hline
\end{tabular}

PHQ-2 Copyright(c) 1999 Pfizer Inc. All rights reserved. Reproduced with permission.

Few data are available on the prevalence of clinical depression among patients seeking eye care. In a survey of optometric practices, Soroka et al. determined that only $0.41 \%$ of optometric patients had a diagnosis of depression, considerably below what would be expected based on the condition's prevalence in the general population and primary-care medical settings. ${ }^{34,35}$ This value, which is based on case histories, does not take into account undiagnosed patients or those unwilling to reveal a diagnosis of depression.

The current study was undertaken to determine the failure rate for the PHQ-2 when administered in a large urban primary-care eye clinic. While the results obtained with a screening device do not indicate the prevalence of clinical depression, they provide a basis for comparison with the findings in other primary-care settings.

\section{METHODS}

\section{Subjects and Procedure}

Patients seated in the waiting area of the Primary Care Clinic of the SUNY, College of Optometry, University Eye Center (UEC) were individually asked by one of the investigators if they would be interested in completing a short survey. The UEC, which is located in midtown Manhattan, provides eye-care services to a diverse urban population.

If the patient agreed, he/she was given the survey and a consent statement along with an envelope in which to place the survey once it was completed. Both the top and bottom of the one-page survey displayed the statement "DO NOT WRITE OR SIGN YOUR NAME ON THIS FORM.” A statement asking the subject to read the accompanying consent prior to completing the survey was also printed on the survey form, as were statements that "answers to the questions on the survey are anonymous" and "no one, including the researchers, will know how you answered the survey questions." The envelopes containing the surveys were subsequently collected by the investigator, who placed them in a bag in the patient's presence. Minimum age for participation in the study was 18 years. The experimental protocol was approved by the SUNY State College of Optometry Institutional Review Board. 
A total of 739 surveys were completed over a period of about two months. Based on the final 797 potential subjects who were approached, the survey completion rate was $69 \%$. About $16 \%$ refused to take the survey, and $2 \%$ of the returned surveys were incomplete. The remaining potential subjects could not complete the survey due to language barriers (6\%), disability (1\%), because they were called in for their exam (3\%) or because they had been dilated and were unable to clearly see the survey items (3\%).

\section{Survey Instrument}

The survey consisted of 10 items, with the first two from the PHQ-2 (Table 1). Included in the remaining items were questions related to demographics (age, gender and ethnicity). A Likert scale was used for the PHQ-2. Data for each completed survey were entered into an SPSS database for analysis.

RESULTS

Table 2 summarizes the demographic characteristics of our sample, which appear to be representative of the population served by the clinic. Results of the PHQ-2 are given in Table 3, which shows that cutoff values of 2, 3, and 4 gave failure rates of $0.29,0.13$ and 0.07 respectively. A score of 3 or higher is normally considered a failing score. ${ }^{23}$

Table 2: Sample demographics

\begin{tabular}{|c|c|}
\hline Demographic & Sample (n, \%) \\
\hline \multicolumn{2}{|l|}{ Age (y) } \\
\hline $18-30$ & $198(26.8 \%)$ \\
\hline $31-45$ & $156(21.1 \%)$ \\
\hline $46-60$ & $230(31.1 \%)$ \\
\hline $61-75$ & $132(17.9 \%)$ \\
\hline 76 or older & $23(3.1 \%)$ \\
\hline \multicolumn{2}{|l|}{ Gender } \\
\hline Male & $264(35.7 \%)$ \\
\hline Female & $474(64.1 \%)$ \\
\hline \multicolumn{2}{|l|}{ Race/Ethnicity } \\
\hline Asian & $69(9.3 \%)$ \\
\hline Black & $227(30.7 \%)$ \\
\hline Caucasian & $278(37.6 \%)$ \\
\hline Hispanic & 117 (15.8\%) \\
\hline Native American & $5(0.7 \%)$ \\
\hline Mixed & $43(5.8 \%)$ \\
\hline
\end{tabular}

Table 3: Frequency distribution of $P H Q-2$ scores

\begin{tabular}{|c|c|c|c|}
\hline $\begin{array}{c}\text { PHQ-2 } \\
\text { Total } \\
\text { Score }\end{array}$ & Frequency & Percent & $\begin{array}{c}\text { Cumulative } \\
\text { Percent }\end{array}$ \\
\hline 6 & 12 & 1.6 & 1.6 \\
\hline 5 & 8 & 1.1 & 2.7 \\
\hline 4 & 34 & 4.6 & 7.3 \\
\hline $3^{*}$ & 40 & 5.4 & 12.7 \\
\hline 2 & 89 & 16.0 & 28.7 \\
\hline 1 & 438 & 59.3 & 40.7 \\
\hline 0 & & 12.0 & 100.0 \\
\hline
\end{tabular}

*Standard cut-off point

\section{DISCUSSION}

A limitation of the current study is that the actual prevalence of clinical depression in the sample was not determined. To do so would have required a structured diagnostic clinical interview of all subjects. The most frequently used of these is the Structured Clinical Interview for DSM-IV (SCID), a lengthy and tedious process that was neither feasible nor appropriate with our sample. ${ }^{36}$ The PHQ-2 failure rate, however, has been determined in patient samples with a known prevalence of clinical depression. These data may be used to infer the prevalence of clinical depression when the PHQ-2 failure rate is known. ${ }^{23,25}$ 
A cutoff score of 3, the standard cutoff score for the PHQ-2, resulted in a 13\% failure rate in our sample taken from an urban primary-care eye clinic. ${ }^{23,25}$ In a sample derived from primary-care medical and obstetrics-gynecology clinics that had a 7\% prevalence of depression as determined with structured interviews, Kroenke et al. found that $15.2 \%$ scored 3 or higher on the PHQ-2. ${ }^{23}$ The PHQ-2 failure rates for the primary-care eye sample in the current study and medical/obstetrics-gynecological samples in previous studies are comparable, suggesting a similar prevalence of clinical depression.

The results reported herein point to a considerably higher prevalence of depression amongst optometric patients than might be suspected based on a survey of optometric practices that found $0.41 \%$ of patients with this condition. $^{34,35}$ This latter figure reflects reliance on case history to determine if depression is present. The $13 \%$ PHQ-2 failure rate found in our sample is similar to that in primary-care medical practices, where $7 \%$ of the patients were diagnosed with depression, leading one to suspect that the prevalence in primary-care optometric practices, particularly urban practices with demographics similar to ours, approaches $7 \%{ }^{23}$

The practical application of these findings to eye-care is complex. Meta-analysis of two-and three-question screening instruments revealed a negative predictive value as low as $93 \%$, indicating that up to $7 \%$ of subjects who pass the test are clinically depressed. ${ }^{28}$ Of greater practical import is that, despite its relatively high specificity, most of the patients who fail the PHQ-2 will not meet the diagnostic criteria for major depression or dysthymia. ${ }^{23}$ Two- and three- question screeners have a positive predictive value of about 0.4, meaning that only four of ten patients who fail the screener are clinically depressed..$^{23,28}$

If the PHQ-2 was used in isolation to screen to depression, without follow-up, it would result in an unjustifiably high over-referral rate. For this reason, it has been recommended that ultra-short screening instruments should only be administered when failing scores can be followed-up with a diagnostic interview or longer survey of higher specificity, such as the PHQ-9, which has additional items specific to the DSM-IV diagnostic criteria, including items related to suicidal ideations. ${ }^{23,28}$ Patients who fail the more comprehensive screening can then be referred for a mental health evaluation. This two-stage screening may be practicable in eye clinics situated in multidisciplinary settings.

In summary, results with the PHQ-2 screening instrument suggest that the prevalence of clinical depression in the primary-care patient population of an urban eye-care clinic may approach that of medical primary-care settings. The availability of appropriate follow-up, however, is of upmost importance when using this screening tool in eyecare practices.

\section{ACKNOWLEDGEMENTS}

This research was supported by a grant from Vision Service Plan (Schwartz) and the SUNY College of Optometry Office of Graduate Studies. A portion of this research was presented at the 2010 meeting of the Association for Research in Vision and Ophthalmology in Ft. Lauderdale, FL. 


\section{REFERENCES}

1. Kessler RC, Berglund P, Demler O, et al. The epidemiology of major depressive disorder: results from the National Comorbidity Survey Replication (NCS-R). JAMA 2003;289:3095-105.

2. Depression in primary care: detection, diagnosis, and treatment. Agency for Health Care Policy and Research. Clin Pract Guidel Quick Ref Guide Clin 1993:1-20.

3. Schwartz SH. The optometrist's role in the management of clinical depressive disorders. Optometry 2007;78:469-73.

4. Williams JW, Jr., Noel PH, Cordes JA, Ramirez G, Pignone M. Is this patient clinically depressed? JAMA 2002;287:1160-70.

5. Murray C, Lopez A. The Global Burden of Disease. Cambridge, MA: Harvard University Press; 1996.

6. Riolo SA, Nguyen TA, Greden JF, King CA. Prevalence of depression by race/ethnicity: findings from the National Health and Nutrition Examination Survey III. Am J Public Health 2005;95:998-1000.

7. Coyne JC, Fechner-Bates S, Schwenk TL. Prevalence, nature, and comorbidity of depressive disorders in primary care. Gen Hosp Psychiatry 1994;16:267-76.

8. Kessler RC, Chiu WT, Demler O, Merikangas KR, Walters EE. Prevalence, severity, and comorbidity of 12-month DSM-IV disorders in the National Comorbidity Survey Replication. Arch Gen Psychiatry 2005;62:617-27.

9. Bostwick JM, Pankratz VS. Affective disorders and suicide risk: a reexamination. Am J Psychiatry 2000;157:1925-32.

10. Practice guideline for the treatment of patients with major depressive disorder (revision). American Psychiatric Association. Am J Psychiatry 2000;157:1-45.

11. DeRubeis RJ, Gelfand LA, Tang TZ, Simons AD. Medications versus cognitive behavior therapy for severely depressed outpatients: mega-analysis of four randomized comparisons. Am J Psychiatry 1999;156:1007-13.

12. Mulrow CD, Williams JW, Jr., Trivedi M, et al. Treatment of depression--newer pharmacotherapies. Evid Rep Technol Assess (Summ) 1999:1-4.

13. Reynolds CF, 3rd, Frank E, Perel JM, et al. Nortriptyline and interpersonal psychotherapy as maintenance therapies for recurrent major depression: a randomized controlled trial in patients older than 59 years. JAMA 1999;281:39-45.

14. Schulberg HC, Katon W, Simon GE, Rush AJ. Treating major depression in primary care practice: an update of the Agency for Health Care Policy and Research Practice Guidelines. Arch Gen Psychiatry 1998;55:1121-7.

15. Screening for depression: recommendations and rationale. Ann Intern Med 2002;136:760-4.

16. Gilbody S, Richards D, Brealey S, Hewitt C. Screening for depression in medical settings with the Patient Health Questionnaire (PHQ): a diagnostic meta-analysis. J Gen Intern Med 2007;22:1596-602.

17. Kroenke K, Spitzer RL, Williams JB. The PHQ-9: validity of a brief depression severity measure. J Gen Intern Med 2001;16:606-13.

18. Albani C, Bailer H, Blaser G, Brahler E, Geyer M, Grulke N. Twoquestion depression-screeners - the solution to all problems? Wien Med Wochenschr 2006;156:185-8.
19. Arroll B, Khin N, Kerse N. Screening for depression in primary care with two verbally asked questions: cross sectional study. BMJ 2003;327:1144-6.

20. Bennett IM, Coco A, Coyne JC, et al. Efficiency of a two-item prescreen to reduce the burden of depression screening in pregnancy and postpartum: an IMPLICIT network study. J Am Board Fam Med 2008;21:317-25.

21. Corson K, Gerrity MS, Dobscha SK. Screening for depression and suicidality in a VA primary care setting: 2 items are better than 1 item. Am J Manag Care 2004;10:839-45.

22. Gjerdingen D, Crow S, McGovern P, Miner M, Center B. Postpartum depression screening at well-child visits: validity of a 2-question screen and the PHQ-9. Ann Fam Med 2009;7:63-70.

23. Kroenke K, Spitzer RL, Williams JB. The Patient Health Questionnaire-2: validity of a two-item depression screener. Med Care 2003;41:1284-92.

24. Li C, Friedman B, Conwell Y, Fiscella K. Validity of the Patient Health Questionnaire 2 (PHQ-2) in identifying major depression in older people. J Am Geriatr Soc 2007;55:596-602.

25. Lowe B, Kroenke K, Grafe K. Detecting and monitoring depression with a two-item questionnaire (PHQ-2). J Psychosom Res 2005;58:163-71.

26. McManus D, Pipkin SS, Whooley MA. Screening for depression in patients with coronary heart disease (data from the Heart and Soul Study). Am J Cardiol 2005;96:1076-81.

27. Mishina H, Hayashino Y, Fukuhara S. Test performance of twoquestion screening for postpartum depressive symptoms. Pediatr Int 2009;51:48-53.

28. Mitchell AJ, Coyne JC. Do ultra-short screening instruments accurately detect depression in primary care? A pooled analysis and meta-analysis of 22 studies. Br J Gen Pract 2007;57:144-51.

29. Olson AL, Dietrich AJ, Prazar G, Hurley J. Brief maternal depression screening at well-child visits. Pediatrics 2006;118:207-16.

30. Pedersen SS, Denollet J, de Jonge P, Simsek C, Serruys PW, van Domburg RT. Brief depression screening with the PHQ-2 associated with prognosis following percutaneous coronary intervention with paclitaxel-eluting stenting. J Gen Intern Med 2009;24:1037-42.

31. Whooley MA, Avins AL, Miranda J, Browner WS. Case-finding instruments for depression. Two questions are as good as many. $\mathrm{J}$ Gen Intern Med 1997;12:439-45.

32. Cutler CB, Legano LA, Dreyer BP, et al. Screening for maternal depression in a low education population using a two item questionnaire. Arch Womens Ment Health 2007;10:277-83.

33. Diagnostic and Statistical Manual on Mental Disorders (DSM-IV), Fourth ed. Washington, DC: American Psychiatric Press; 1994.

34. Soroka M, Krumholz D, Bennett A. The practice of optometry: National Board of Examiners in Optometry survey of optometric patients. Optometry 2006;77:427-37.

35. Soroka M, Krumholz D, Bennett A. The practice of optometry: National Board of Examiners in Optometry survey of optometric patients. Optom Vis Sci 2006;83:625-36.

36. Spitzer R, Williams J, Gibbon M, First M. The Structured Clinical Interview for DSM-III-R (SCID), I. Arch Gen Psychiatry 1992;49:624-9. 